\title{
Pengembangan sistem jamina halal produk minuman herbal instan di industri kecil menengah (ikm) "dia"
}

\author{
Developing Halal Assurance System for Instant Herbal Drinks Produced by \\ Small Medium Enterprise (SME) "DIA" \\ Teti Estiasih ${ }^{1)}$, Kgs. Ahmadi ${ }^{2)}$, Harijono ${ }^{1)}$ \\ ${ }^{1)}$ Program Studi Ilmu dan Teknologi Pangan, Fakultas Teknologi Pertanian Universitas \\ Brawijaya, Jl. Veteran, Malang \\ ${ }^{2)}$ Program Studi Teknologi Industri Pertaian, Fakutas Pertanian, Universitas Tribhuwana \\ Tunggadewi, Jl. Tlogowarna, Tologomas, Malang \\ Penulis korespiondensi: email teties@yahoo.co.id; teties@ub.ac.id
}

Dikirim: 20/09/2019; ditinjau: 21/09/2019; disetujui: 30/09/2019

\begin{abstract}
Indonesian law obliges that all marketed, distributed, and trade products in the territory of Indonesia should have comply halal requiremnets. Small and Medium Enterprise (SME) DIA produces instant herbal drink products with the largest consumer is being Muslim. In accordance with the law, thatall products are required to halal certified and have a halal logo on the label, the SME DIA also prepares for halal certification. To certify halal, a halal assurance system must be implemented. Development of halal assurance system is required for small and medium industries in order to halal certification. Development of the halal assurance system is based on the HAS 23000 guide from LPPOM MUI. In fulfillment of HAS 23000, SME DIA has implemented 11 clausuls that are halal policy, halal management team, materials, products, production facilities, training and education, written standardoperating procedures, traceability, uncomplied halal product handling, internal audit, and management review. HCCCP analysis shows that no halal critical points in producing instant herbal drinks at SME DIA.
\end{abstract}

Keywords: certification, halal, halal assurance system, instant herbal drink

\begin{abstract}
ABSTRAK
Undang-undang No. 33 Tahun 2014 tentang Jaminan Produk Halal mengamanatkan dalam Pasal 4 bahwa semua produk yang masuk, beredar, dan diperdagangkan di wilayah Indonesia wajib bersertifikat halal. Produk industri kecil menengah (IKM) DIA merupakan produk minuman herbal instan dengan konsumen terbesar adalah muslim. Sesuai dengan undang-undang, bahwa semua produk pangan wajib sertifikasi halal dan mencantumkan label halal pada produknya, maka IKM DIA juga merencanakan untuk sertifikasi halal. Untuk mensertifikasi halal tersebut, sistem jaminan halal harus diimplementasikan. Pengembangan sistem jaminan halal diperlukan bagi industri kecil menengah dalam rangka sertifikasi halal. Pengembangan sistem jaminan halal tersebut mengacu kepada panduan HAS 23000 dari LPPOM MUI. Dalam pemenuhan HAS 23000 tersebut, IKM DIA telah melaksanakan 11 klausul yang disyaratkan yang meliputi kebijakan halal, tim manajemen halal, bahan, produk, fasilitas produksi, pelatihan dan edukasi, prosedur tertulis aktivitas kritis, kemampuan telusur, penanganan produk yang tidak memenuhi kriteria, audit internal, dan kaji ulang manajemen. Hasil analisis HCCCP pada proses produksi minuman herbal instan di IKM DIA tidak ditemukan adanya halal critical point.
\end{abstract}

Kata kunci: halal, minuman herbal instan, sertifikasi, sistem jaminan halal, 


\section{PENDAHULUAN}

Penekanan pada pentingnya produk halal kini semakin berkembang dan dengan cepat menjadi kekuatan pasar yang baru. Isu halal menjadi masalah utama dan mempengaruhi persepsi konsumen tentang suatu produk. Tuntutan halal juga telah memandu bagaimana proses bisnis harus dijalankan karena isu halal tidak lagi murni masalah agama. Halal telah menjadi simbol dari proses penjaminan mutu produk (Hanzaee dan Ramezani, 2011).

Keaslian halal dapat diverifikasi menggunakan berbagai alat analisis laboratorium (Wilson dan Liu 2010; Nakyinsige, Man dan Sazili, 2012) dan dapat dilakukan dengan pelabelan dan sertifikasi produk (Badruldin et al., 2012). Kepedulian konsumen terhadap makanan halal semakin meningkat seperti saat ini citra industri makanan halal telah ternoda akibat meningkatkan terjadinya sertifikasi halal yang curang dan kontaminasi fisik produk makanan halal (Annabi dan Ahmed, 2015; Hasan dan Hanif, 2017).

Konsep halal (terutama untuk pangan) mencakup semua aspek mulai dari bahan baku sampai produk disajikan. Halal mengharuskan produk pangan bergizi dan dibuat dari bahan-bahan yang diijinkan, bersih, dan higienis. Konsumen muslim juga menuntut produk yang sehat dan berkualitas, yang juga harus sesuai dengan persyaratan syariah. Sertifikat halal dapat memainkan peran penting untuk meyakinkan konsumen bahwa produk telah mendapatkan kondisi yang diperlukan dari produk halal (Hanzaee dan Ramezani, 2011).

Sebagian besar produk yang dijual secara islami negara-negara dianjurkan untuk memiliki sertifikat halal karena itu menunjukkan produksi mengikuti Hukum Syariah (Fuseini, Knowles, Hadley, \& Wotton, 2016). Konsep halal mencakup setiap aspek kehidupan Muslim (Majid et al., 2015). Karena jumlah Muslim di dunia mendekati 1,6 miliar dan ini adalah diperkirakan akan meningkat $30 \%$ dari populasi dunia pada tahun 2025, pasar untuk produk halal sangat luas. Banyak masyarakat Islam menganggap sertifikat halal sebagai faktor penting yang mempengaruhi kenginan dalam pembelian beli (Ali et al., 2017; Majid, Sabir dan Ashraf, 2015). Sertifikat halal juga dapat menunjukkan bahwa produk bernilai tinggi (Nasirun et al., 2019).

Penelitian sebelumnya oleh Mohamed et al. (2008) menyatakan bahwa sertifikasi halal dapat mengurangi ketidakpastian dan meningkatkan kepercayaan dan kepercayaan konsumen halal. Rajagopal et al. (2011) dan Bakar et al. (2016) menyatakan bahwa makanan bersertifikat halal memberikan jaminan bahwa makanan telah diproduksi, diproses dan ditangani dengan aman sesuai dengan persyaratan agama. Tidak hanya itu, sertifikasi halal produk makanan dapat digunakan sebagai alat pemasaran untuk menarik lebih banyak basis konsumen.

Undang-undang No. 33 Tahun 2014 tentang Jaminan Produk Halal mengamanatkan dalam Pasal 4 bahwa semua produk yang masuk, beredar, dan diperdagangkan di wilayah Indonesia wajib bersertifikat halal. Menurut LPPOM MUI (2008), memproduksi produk halal adalah bagian dari tanggungjawab perusahaan kepada konsumen muslim. Di Indonesia, untuk memberikan keyakinan kepada konsumen bahwa produk yang dikonsumsi adalah halal, maka perusahaan perlu memiliki Sertifikat Halal MUI.

Hal ini mendorong semua usaha pangan baik olahan mau segar untuk mensertifikasi produknya. Menurut undangundang tersebut, pengertian sertifikasi halal adalah sertifikat halal adalah pengakuan kehalalan suatu produk yang dikeluarkan oleh BPJPH berdasarkan fatwa halal tertulis yang dikeluarkan oleh MUI. Dalam proses sertifikasi tersebut suatu perusahaan harus menyiapkan sistem jaminan halal (SJH) yang menjamin bahwa produk yang dihasilkan adalah halal. Penerapan sistem 
jaminan halal tersebut harus sesuai dengan lingkup perusahaan.

Saat ini LP POM MUI telah menerapkan Halal Assurance System (HAS) 23000. HAS 23000 adalah dokumen yang berisi persyaratan sertifikasi halal LPPOM MUI. HAS 23000 terdiri dari 2 bagian, yaitu Bagian I tentang Persyaratan Sertifikasi Halal yang berisi Kriteria Sistem Jaminan Halal (HAS 23000:1) dan Bagian (II) tentang Persyaratan Sertifikasi Halal yang berisi Kebijakan dan Prosedur (HAS 23000:2) (LP POM MUI, 2017a).

Produk industri kecil menengah (IKM) DIA merupakan produk minuman herbal instan dengan konsumen terbesar adalah muslim. Sesuai dengan UU No. 33 Tahun 2014, bahwa semua produk pangan wajib sertifikasi halal dan mencantumkan label halal pada produknya, maka IKM DIA juga merencanakan untuk sertifikasi halal. Untuk mensertifikasi halal tersebut, sistem jaminan halal harus diimplementasikan. Menurut Purnomo (2010), perusahaan yang telah mensertifikasikan halal untuk produknya dituntut menyiapkan suatu sistem untuk menjamin kesinambungan proses produksi halal secara konsisten. Sistem inilah yang disebut sebagai sistem jaminan halal. Tujuan dari kegiatan ini adalah menyusun dan menerapkan sistem jaminan halal untuk skala industri kecil menengah (IKM) dengan produk yang dihasilkan berupa minuman herbal instan. Proses sertifikasi untuk IKM DIA dilakukan melalui CEROL-SS23000 yaitu system pelayanan sertifikasi halal LPPOM MUI secara online. Dengan system ini perusahaan dapat mengajukan permohonan sertifikasi halal produk secara online tanpa batas waktu dan tempat (LPPOM MUI, 2017b).

\section{METODE PELAKSANAAN}

Pada kegiatan ini dilakukan penyusunan sistem jaminan halal dan pendampingan untuk implementasinya. Langka-langah penyusunan sistem jaminan halal tersebut sesuai dengan panduan dari LPPOM MUI (n.a.) yaitu sebagai berikut:
HAS 23000:1 Kriteria sistem jaminan halal

Kebijakan halal

Manajemen Puncak harus menetapkan Kebijakan Halal dan mensosialisasikan kebijakan halal kepada seluruh pemangku kepentingan (stake holder) perusahaan.

\section{Tim manajemen halal}

Manajemen Puncak harus menetapkan Tim Manajemen Halal yang mencakup semua bagian yang terlibat dalam aktivitas kritis serta memiliki tugas, tanggungjawab dan wewenang yang jelas.

\section{Pelatihan dan edukasi}

Perusahaan harus mempunyai prosedur tertulis pelaksanaan pelatihan. Pelatihan internal harus dilaksanakan minimal setahun sekali dan pelatihan eksternal harus dilaksanakan minimal dua tahun sekali.

\section{Bahan}

Bahan yang digunakan dalam pembuatan produk yang disertifikasi tidak boleh berasal dari bahan haram atau najis. Perusahaan harus mempunyai dokumen pendukung untuk semua bahan yang digunakan, kecuali bahan tidak kritis atau bahan yang dibeli secara retail.

\section{Produk}

Karakteristik/profil sensori produk tidak boleh memiliki kecenderungan bau atau rasa yang mengarah kepada produk haram atau yang telah dinyatakan haram berdasarkan fatwa MUI. Merk/nama produk yang didaftarkan untuk disertifikasi tidak boleh menggunakan nama yang mengarah pada sesuatu yang diharamkan atau ibadah yang tidak sesuai dengan syariah Islam. Produk pangan eceran (retail) dengan merk sama yang beredar di Indonesia harus didaftarkan seluruhnya untuk sertifikasi, tidak boleh jika hanya didaftarkan sebagian.

\section{Fasilitas produksi}

Untuk Industri pengolahan meliputi:

a. Fasilitas produksi harus menjamin tidak adanya kontaminasi silang dengan bahan/produk yang haram/najis;

b. Fasilitas produksi dapat digunakan secara bergantian untuk menghasilkan produk yang disertifikasi dan produk yang tidak disertifikasi selama tidak mengandung 
bahan yang berasal dari babi/turunannya, namun harus ada prosedur yang menjamin tidak terjadi kontaminasi silang.

\section{Prosedur tertulis aktivitas kritis}

Perusahaan harus mempunyai prosedur tertulis mengenai pelaksanaan aktivitas kritis, yaitu aktivitas pada rantai produksi yang dapat mempengaruhi status kehalalan produk. Aktivitas kritis dapat mencakup seleksi bahan baru, pembelian bahan, pemeriksaan bahan datang, formulasi produk, produksi, pencucian fasilitas produksi dan peralatan pembantu, penyimpanan dan penanganan bahan dan produk, transportasi, pemajangan (display), aturan pengunjung, penentuan menu, pemingsanan, penyembelihan, disesuaikan dengan proses bisnis perusahaan (industri pengolahan, RPH, restoran/katering/dapur). Prosedur tertulis aktivitas kritis dapat dibuat terintegrasi dengan prosedur sistem yang lain.

\section{Kemampuan telusur (traceability)}

Perusahaan harus mempunyai prosedur tertulis untuk menjamin kemampuan telusur produk yang disertifikasi berasal dari bahan yang memenuhi kriteria (disetujui LPPOM MUI) dan diproduksi di fasilitas produksi yang memenuhi kriteria (bebas dari bahan babi/ turunannya).

\section{Penanganan produk yang tidak memenuhi kriteria}

Perusahaan harus mempunyai prosedur tertulis untuk menangani produk yang tidak memenuhi kriteria, yaitu tidak dijual ke konsumen yang mempersyaratkan produk halal dan jika terlanjur dijual maka harus ditarik.

\section{Audit internal}

Perusahaan harus mempunyai prosedur tertulis audit internal pelaksanaan $\mathrm{SJH}$. Audit internal dilakukan setidaknya enam bulan sekali dan dilaksanakan oleh auditor halal internal yang kompeten dan independen. Hasil audit internal disampaikan ke LPPOM MUI dalam bentuk laporan berkala setiap 6 (enam) bulan sekali.

\section{Kaji ulang manajemen}

Manajemen Puncak atau wakilnya harus melakukan kaji ulang manajemen minimal satu kali dalam satu tahun, dengan tujuan untuk menilai efektifitas penerapan $\mathrm{SJH}$ dan merumuskan perbaikan berkelanjutan.

\section{Kebijakan dan prosedur sertifikasi halal}

Kebijakan dan prosedur harus dipenuhi oleh perusahaan yang mengajukan sertifikasi halal.

\section{HASIL DAN PEMBAHASAN}

Pengembangan sistem jaminan halal di IKM DIA sesuai dnegan langkah-langkah yang telah ditetapkan dalam Panduan Sistem Jaminan Halal dari LP POM mUI yang tertinag di bagian Metode. Pengembangan tersebuta dalah sebagai berikut:

HAS 23000:1 Kriteria sistem jaminan halal

\section{Kebijakan halal}

Pimpinan sekaligus pemilik IKM DIA telah menetapkan kebijakan halal bahwa semua Standard Operating Procedure (SOP) yang telah dibuat terkait dengan sistem jaminan halal harus diterapkan. SOP tersebut telah disosialisasikan kepada seluruh personal yang ada di IKM DIA. Kebijakan halal tersebut dimaklumat yaitu:

IKM DIA bertekad untuk hanya memproduksi dan memasarkan produk halal secara konsisten dalam rangka memenuhi kebutuhan konsumen serta mengutamakan kepuasan pelanggan melalui inovasi.

Kebijakan tersebut dicapai melalui langkahlangkah penerapan sebagai berikut:

1. Menjamin seluruh produk yang dibuat disertifikasi halal LPPOM MUI

2. Menjamin seluruh bahan yang digunakan dalam pembuatan produk adalah halal

3. Menjamin sistem produksi adalah bersih dan bebas dari bahan yang tidak halal dan najis

4. Melatih, mengembangkan dan melibatkan seluruh stakeholder perusahaan guna memahami sistem jaminan halal

5. Menyediakan sumber daya yang diperlukan untuk penyusunan, penerapan, 
dan perbaikan berkelanjutan sistem jaminan halal

6. Melakukan sosialisasi kebijakan halal ke seluruh pemangku kepentingan perusahaan melalui media sosilasiasi seperti pelatihan, briefing, memo internal, spanduk, poster, atau bentuk sosialisasi lain sesuai dengan kebutuhan perusahaan

IKM DIA sebelum mengajukan sertifikasi halal juga sudah tersertifikasi HACCP (Hazard Analyziz and Critical Control Point). Artinya proses produksi yang telah diterapkan oleh IKM DIA telah mampu menjamin bahwa produk yang dihasilkan adalah aman. Menurut Wallace etal. (2014) HACCP merupakan elemen kunci dalam manajemen keamanan pangan modern yang meliputi perancangan, implementasi, pengendalian, dan manajemen HACCP yang krusial bagi keamanan produk pangan. Perusahaan pangan harus menerapkan HACCP.

\section{Tim manajemen halal}

Pemilik sekaligus pimpinan IKM DIA selaku manajemen puncak telah membentuk tim untuk manajemen halal. Tim manajemen ini mempunyai tugas pokok dan fungsi terutama dalam implementasi sistem jaminan halal. Untuk implementasi tersebut, langkah pertama yang dilakukan adalah penyusunan dokumen halal termasuk penyusunan HalalComliance Critical Control Points (HCCCP), yaitu identifikasi titik-titik kritis dalam pengolahan (Kamaruddin et al., 2012) minuman herbal instan yang dapat mempengaruhi kehalalal produk.

\section{Pelatihan dan edukasi}

Tim Manajemen Halal setelah menerapkan sistem jaminan halal untuk produksi minuman herbal instan melakukan sosialisasi tentang sistem jaminan halal. Juga dilakukan pelatihan kepada karyawan bagaiamna pengendalian yang harus dilakukan sehingga produk yang dihasilkan mulai dari bahan baku sampai produk akhir terhindari dari potensi ketidakhalalan dan najis.

\section{Bahan}

Bahan baku yang digunakan dalam proses produksi minuman herbal instan adalah empon-empon seperti jahe, kunyit putih, temulawak, kencur dan lainnnya serta gula pasir. Tidak ada bahan tambahan lainyang digunakan oleh IKM DIA. Untuk menjamin bahwa produk minuman herbak instan tersbeut halal, maka bahan baku yang diguankan juga harus dipastikan halal dan bebas dari najis. Gula pasir diperoleh IKM DIA dari pasar dan tidak ada penyuplai khusus untuk bahan baku tersebut. Untuk menjamin kehalalan produk, gula pasir yang digunakan adalah gula pasir yang sudah tersertifiaksi halal.

Bahan baku empon-empon diperoleh dari petani langsung dalam kondisi sudah bersih dan dicuci serta bebas dari kotoran. Inspeksi kebersihan empon-empon penting dilakukan untuk menjamin bahwa emponempon bebas najis. Untuk itu IKM DIA juga melakukan sosialisasi sistem jaminan halal kepada penyuplai empon-empon sebagai salah satu pemangku kepentingan di IKM DIA.

\section{Produk}

Produk minuman herbal instan dari IKM DIA mempunyai bau dan rasa yang khas dan tidak mengarah kepada produk haram atau yang telah dinyatakan haram berdasarkan fatwa MUI. Merek dan nama produk yang sudah didaftarkan dalam sistem CEROL-SS 23000 adalah merek DIA yang tdaik mengarah kepada sesuatu yang diharamkan atau ibadah yang tidak sesuai dengan syariah Islam. Produk IKM DIA terdiri dari berbagai varian minuman herbal instan tergatung dari jenis bahan bakunya seperti jahe instan, temulawak instan, jahe merah isntan dan lainnya, semua sudah didaftarkan dalam sistem CEROL-SS 23000 karena mempunyai merak yang sama. Ada 11 produk yang sudah didaftarkan untuk sertifikasi halal ini.

\section{Fasilitas produksi}

IKM DIA telah tersertifiaksi HACCP yang menunjukkan bahwa fasilitas produksi sudah memenuhi persayaratan fasilitas produksi menurut GMP (Good Manufacturing Practices) dan HACCP. GMP merupakan prasyarat untuk HACCP. Di dalam GMP tersebut salah satu syarat 
adalah fasilitas produksi yang meliputi lokasi, bangunan, peralatan, serta hygiene dan sanitasi. Sejalan dnegan HACCP, sistem jaminan halal yang dibuat oleh IKM DIA mensyaratkan bahwa fasilitas produksi tidak boleh memungkinkan adanya kontaminasi silang. IKM DIA hanya memproduksi satu tipe produk dengan bahan baku yang disyaratkan juga halaldan bebas najis, sehingga tdiak ada proses produksi produk lain yang memungkinkan terjadinya kontaminasi silang. Penerapan HACCP termasuk didalamnya sistem hygiene dan sanitasi menjamin bahwa produk IKM DIA bebas dari kotoran yang berbahaya sekaligus sejalan dengan penerapan Halal CCP juga bebas dari kontamiansi bahan najis akibat sanitasi yang tidak tepat seperti tercemar dari kotoran hewan. Peralatan produksi juga dipelihara dengan baik dan tidak digunakan secara bergantian dengan bahan yang najis seperti babi dan turunannya.

\section{Prosedur tertulis aktivitas kritis}

Tim Manajemen Halal di IKM DIA telah menyusun Halal Compliance Critical Control Point (HCCCP)dan mengidentifikasi titik bahaya bagi kehalalan produk minuman herbal instan. dari rposes pembuatan minuman herbal instan, tidak ada halal critical control point (CCP) dalam proses produksi minuman herbal instan. Menurut Razaly et al. (2016), penentuan Halal Critical Points (HCP) merupakan elemen kunci yang harus diimplementasikan pada penerapan HAS (HalalAssuranceSystem). HCP harus diidentifiaksi, dikontrol, dan dikendalikan untuk mencegah dan mengatasi potensi bahaya bagi kehalalan. Aktivitas kritis dapat mencakup penerimaan bahan baku, pembelian bahan, formulasi produk, produksi, pencucian fasilitas produksi dan peralatan pembantu, penyimpanan dan penanganan bahan dan produk, transportasi, dan pemasaran (LPOM UI 2017).

\section{Kemampuan telusur (traceability)}

Penelusuran merupakan salah satu kunci penting untuk menjamin bahwa produk yang dihasilkan IKM DIA adlaah halal. IKM DIA telah mempunyai prosedur tertulis dalam bentuk SOP untuk menjamin ketelusuran bahan baku yang digunakan.

\section{Penanganan produk yang tidak memenuhi kriteria}

IKM DIA telah mempunyai prosedur tertulis (SOP) untuk menangani produk cacat halal yaitu produk yang tdiak memenuhi kriteria sebagai produk halal. Prosedur penarikan produk tidak halal juga sudah dibuat dalam bentuk SOP penarikan produk,

\section{Audit internal}

Untuk menjamin bahwa sistem jaminan halal dijalankan dan diterapkan, maka telah merencanakan audit internal secara berkala setiap enam bulan sekali. Untuk audit eksternal akan dilakukan sesuai dengan masa berlaku sertifikat halal yaitu setiap dua tahun sekali.

\section{Kaji ulang manajemen}

Pimpinan IKM DIA telah merencanakan untuk melakukan tinjauan manajemen sekali dalam satu tahun. Selain tinjauan tentang impelementasi sistem jaminan halal, tinjauan manajemen ini sekaligus dengan tinjauan manajemen impelementasi HACCP. Tinjauan manajemen ini penting dilakukan supaya IKM DIA selalu melakukan perbaikan berkelanjutan dalam implementasi sistem jaminan halal.

\section{HAS 23000:2 Kebijakan dan prosedur sertifikasi halal}

IKM DIA telah mendaftarkan untuk sertifikasi halal dari CEROL-SS 23000. Pemenuhan terhadap syarat sertifoaksi telah dilakukan. Demikian pula kebijakan halal yang telah ditetapkan juga telah diimplementasikan.

\section{KESIMPULAN}

Pengembangan sistem jaminan halal diperlukan bagi industri kecil menengah dalam rangka sertifikasi halal. Pengembangan sistem jaminan halal tersebut mengacu kepada panduan HAS 23000 dari LPPOM MUI. Dalam pemenuhan HAS 23000 tersebut, IKM DIA telah melaksanakan 11 klausul yang disyaratkan yang meliputi kebijakan halal, tim 
manajemen halal, bahan, produk, fasilitas produksi, pelatihan dan edukasi, prosedur tertulis aktivitas kritis, kemampuan telusur, penanganan produk yang tidak memenuhi kriteria, audit internal, dan kaji ulang manajemen. Hasil analisis HCCCP pada proses produksi minuman herbal instan di IKM DIA tidak ditemukan adalanya halal critical point.

\section{DAFTAR PUSTAKA}

Ali, A., Xiaoling, G., Sherwani, M., \& Ali, A. (2017). Factors affecting Halal meat purchase intention: evidence from international muslim students in China. British Food Journal, 119(3), 527-541.

Annabi, C. A., \& Ahmed, J. L. (2015). Halal Beef Handling in Nigeria: The Abattoir Workers' Perspective. Journal of Emerging Economies \& Islamic Research, 3(2).

Badruldin, B., Mohamed, Z., Sharifuddin, J., Rezai, G., Mahir Abdullah, A., Abd Latif, I., \& Ghazali Mohayidin, M. (2012). Clients' perception towards JAKIM service quality in Halal certification. Journal of Islamic Marketing, 3(1), 59-71.

Bakar, N. A., Peszynski, K., Azizan, N., Sundram, K., \& Pandiyan, V. (2016). Abridgment of Traditional Procurement and E-Procurement: Definitions, Tools and Benefits. Journal of Emerging Economies \& Islamic Research, 4(1).

Fuseini, A., Knowles, T. G., Hadley, P. J., \& Wotton, S. B. (2016). Halal stunning and slaughter: Criteria for the assessment of dead animals. Meat Science, 119, 132-137.

Hanzaee, K.H., \& Ramezani, M.R. (2011). Intention to halal products in the world markets. Interdisciplinary Journal of Research in Business, 1(5), 1-7.

Hassan, F., \& Hanif, A.(2017). Halal issues in processed food:Misuse of the halal logo. Journal of Emerging Economies and Islamic Research, 5(3), 1-5.
Kamaruddin, R., Iberahim, H., \& Shabudin, A.(2012). Halal compliance critical control points analysis of processed foods. IEEE Business, Engineering \& Industrial Applications Colloquium (BEIAC), 383-387.

LPPOM MUI. (2008). Panduan umum sistem jaminan halal LPPOM MUI. Lembaga Pengkajian Pangan ObatObatan Dan Kosmetika Majelis Ulama Indonesia.

LPPOM MUI. (2017a). Persyaratan sertifikasi halal MUI. Retrieved from: www.halalmui.org/mui14/index.php/m ain/go_to_section/58/1366/page/1. Tanggal akses 28 September 2019.

LPPOM MUI. (2017b). Sistem pelayanan sertifikasi halal online (CEROLSS23000). Retrived from: http://elppommui.org/documents/Manual_CE ROL-Manufacturing_(IDN-2.3).pdf. Tanggal akses 1 Oktober 2019.

Majid, M. B., Sabir, I., \& Ashraf, T. (2015). Consumer purchase intention towards halal cosmetics \& personal care products in Pakistan. Global of Research in Business \& Management, 1(1), 45-53.

Mohamed, Z., Rezai, G., Shamsudin, M. N., \& Chiew, E. F. C. (2008). Halal logo and consumers' confidence: What are the important factors. Economic and Technology Management Review, 3(1), 37-45.

Mohamed, Z., Shamsudin, M. N., \& Rezai, G. (2013). The effect of possessing information about halal logo on consumer confidence in Malaysia. Journal of International Food \& Agribusiness Marketing, 25(sup1), 73-86.

Nakyinsige, K., Man, Y. B. C., \& Sazili, A. Q. (2012). Halal authenticity issues in meat and meat products. Meat science, 91(3), 207-214.

Nasirun, N., Noor, S. M., Sultan, A. A., \& Haniffiza, W. M. H. W. M. (2019). Role of marketing mix and halal certificate towards purchase intention 
of agro based products. International Journal, 2(7), 37-46.

Purnomo, D.(2010). Prinsip sistem jaminan halal dan kaitannya dengan konsep TQM. Retrieved from: https://agroindustry.wordpress.com/20 10/10/28/prinsip-sistem-jaminan-halaldan-kaitannya-dengan-konsep-tqm. Tanggal akses 28 September 2019.

Rajagopal, S., Ramanan, S., Visvanathan, R., \& Satapathy, S. (2011). Halal certification: implication for marketers in UAE. Journal of Islamic Marketing, 2(2), 138-153.

Razaly, M.M., Zakaria, Z., Ismail, S.Z., \& Jusoh, A.(2016). The determination of halal critical point in halal certified chicken slaughterhouses and its significance. Proceedings of the $3 r d$ International Halal Conference (INHAC 2016), 259-271.

Rezai, G., Mohamed, Z., \& Shamsudin, M. N. (2012). Assessment of consumers' confidence on halal labelled manufactured food in Malaysia. Pertanika Journal of Social Science \& Humanity, 20(1), 33-42..

Undang-Undang Republik Indonesia Nomor 33 Tahun 2014 tentang Jaminan Produk Halal

Wallace, C.A., Holyoak, L., Powell, S.C., \& Dykes, F.C. (2014). HACCP-The difficulty with hazard analysis. Food Control, 35(1), 233-240.

Wilson, J. A., \& Liu, J. (2010). Shaping the halal into a brand?. Journal of Islamic Marketing, 1(2), 107-123. 